\title{
Analysis of Surface Permanent Magnet Machines With Fractional-Slot Concentrated Windings
}

\author{
Ayman M. El-Refaie, Student Member, IEEE, Thomas M. Jahns, Fellow, IEEE, and Donald W. Novotny, Fellow, IEEE
}

\begin{abstract}
This paper presents a closed-form analytical technique for analyzing surface PM machines equipped with fractional-slot concentrated windings. Since this class of winding configuration deviates significantly from conventional sinusoidal distributions, classical steady-state phasor or $d q$ analytical techniques cannot be used to provide accurate results. The presented analytical model provides a fast and reliable method to analyze and compare candidate machine designs. Stator slotting effects are taken into consideration and a wide range of concentrated winding configurations can be analyzed. This technique is capable of analyzing the machine both below (constant-torque) and above (flux-weakening) base speed. Average torque, cogging torque, and ripple torque are all evaluated. Analytical results are verified using finite element analysis.
\end{abstract}

Index Terms-Analysis, closed-form, concentrated, fluxweakening, fractional-slot, permanent magnet, surface, synchronous, windings.

\section{INTRODUCTION}

$\mathbf{F}$ LUX weakening of conventional surface permanent magnet (SPM) synchronous machines with distributed windings is generally not very effective for achieving wide ranges of constant power operation [1] and [2]. The SPM machine parameter that is the best indicator of its flux weakening potential is the characteristics current, $I_{\mathrm{ch}}$ defined as follows:

$$
I_{\mathrm{ch}} \equiv \frac{\Psi_{m}}{L_{d}} \quad[\text { Arms }]
$$

where $\Psi_{m}$ is the rms magnet flux linkage and $L_{d}$ is the $d$-axis inductance (equal to the $q$-axis inductance for SPM machines). More specifically, it is widely recognized that a high value of characteristic current compared to the machine rated current $I_{R}$ indicates that the machine's flux weakening capabilities will be poor [1]. Unfortunately, this is typically the case for conventional SPM machines. Considering first the numerator in (1), the magnet flux linkage $\Psi_{m}$ is typically high on a per-unit basis because it provides the sole source of rotor excitation for torque production. Turning attention to the denominator, the per-unit inductance of conventional SPM machines tends to be quite low because the magnets behave as large air gaps in the machine's magnetic circuit. In combination, these trends lead

Manuscript received March 7, 2005; revised June 12, 2005. This was supported in part by the MIT/Industry Consortium on Advanced Automotive Electrical and Electronic Components and Systems. Paper No. TEC-00080-2005.

A. M. El-Refaie is with Electrical Machines \& Drives Lab, GE Global Research Center, 1 Research Circle, Niskayuna, NY 12309-1027 USA (e-mail: elrefaie@research.ge.com).

T. M. Jahns and D. W. Novotny are with the Department of Electrical and Computer Engineering, University of Wisconsin-Madison, Madison, WI 53706 USA (e-mail: jahns@engr.wisc.edu; novotny@engr.wisc.edu).

Digital Object Identifier 10.1109/TEC.2005.858094

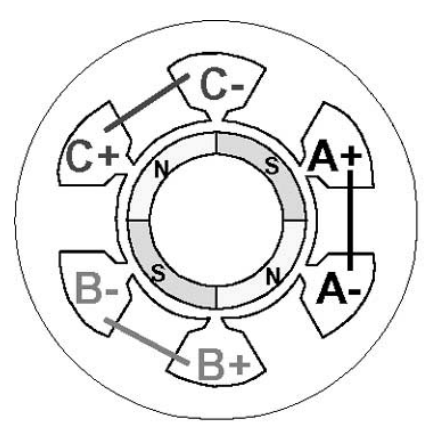

(a)

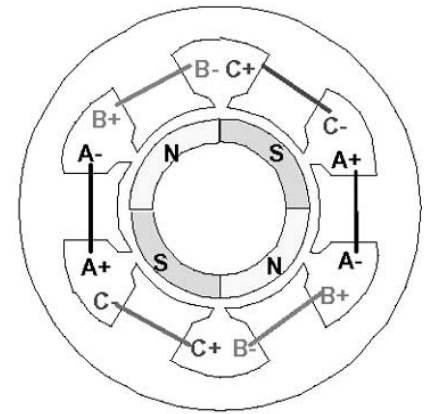

(b)
Fig. 1. Two major classes of concentrated-winding configurations. (a) Singlelayer winding. (b) Double-layer winding.

to high values of characteristic current and poor flux weakening performance.

It has been shown [3] that the optimal flux-weakening condition (i.e., $I_{\mathrm{ch}}=I_{R}$ ) can be achieved in SPM machines by using fractional-slot concentrated windings in place of the distributed windings. One of the major challenges in applying concentrated windings is that classical phasor and $d q$ analytical techniques cannot be used because the concentrated winding configuration deviates significantly from conventional sinusoidal distributions [4].

Finite element analysis (FEA) has been adopted as the principal analytical tool in recent papers that address the use of concentrated windings in SPM machines [5]-[8]. While FEA is capable of providing accurate results, it is computationally time-consuming and does not easily provide insights into the performance effects of key design parameters.

An analytical model for an SPM brushless dc machine with concentrated windings has been presented in [9]. However, this work is limited to addressing one very popular winding configuration for this type of machine using stator windings with 0.5 slot/pole/phase. This concentrated winding configuration can actually be analyzed as a special class of distributed three-phase windings with a coil span of $120^{\circ}$.

The goal of this paper is to present a general closed-form technique for analyzing surface PM machines equipped with fractional-slot concentrated windings. This approach takes advantage of some established analytical techniques to analyze SPM machines with a wide range of fractional-slot concentrated winding configurations. Concentrated-winding machines with both single-layer and double-layer stator windings (Fig. 1) can be analyzed using this technique [5].

Stator slotting effects are incorporated into the analysis, making it possible to calculate the cogging torque and ripple torque in addition to the average torque. Performance characteristics 


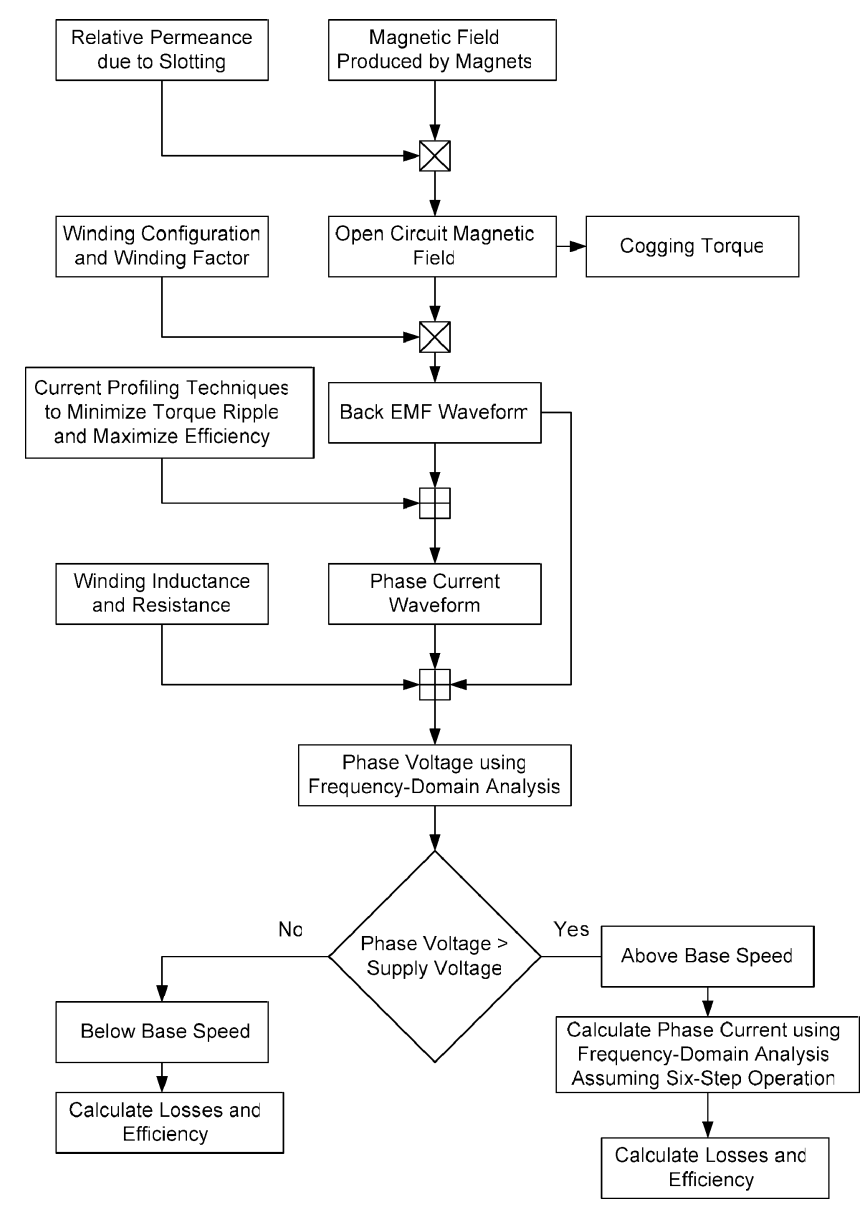

Fig. 2. Analysis flowchart for SPM machines with fractional-slot concentrated windings.

in both the constant-torque and the flux-weakening operating regimes can be analyzed using this approach. Machine losses and efficiency are also evaluated. Analytical results are verified using finite element analysis.

\section{ANALYTICAL PROCEDURE}

The flowchart shown in Fig. 2 summarizes the procedure that has been developed for analyzing SPM machines with fractional-slot concentrated windings. In this section, the various blocks of this flowchart will be discussed.

\section{A. Open Circuit Magnetic Field}

Several authors have proposed analytical models for calculating the air-gap magnetic field in surface PM machines. The model chosen for this analysis [10] is very useful since it can be used for both internal or external rotor structures with either radial or parallel magnetization. One of the important assumptions of this model is that the stator iron is not saturated. Fortunately, this is typically the case in SPM machines because of the large effective air gap contributed by the rotor magnets.

Although, this technique can be used to calculate both the radial and tangential magnetic field components, the analytical approach developed in this paper will only use the radial component. The radial field component produced by the magnets can be represented as a Fourier series

$$
B_{\text {magnet }}\left(\theta_{s}, \theta_{r}, r_{g}\right)=\sum_{n=1,3,5 \ldots}^{\infty} B_{n}\left(r_{g}\right) \cos n p\left(\theta_{s}-\theta_{r}\right)[T]
$$

where $B_{n}$ is the $n$th spatial harmonic component of the flux density [T], $r_{g}$ is the air gap radius $[\mathrm{m}], \theta_{s}$ is the angle [mech $\mathrm{rad}$ ] along the stator periphery, $\theta_{r}$ is the rotation angle [mech $\mathrm{rad}]$ of the rotor, and $p$ is the number of pole pairs.

For machines with slotted stators, several models have been presented to account for the slotting effects in electrical machines. Most of these models are based on conformal transformation techniques. The model chosen for this analysis [11] assumes that the stator slots are infinitely deep rectilinear slots. This model is appropriate for stator designs having a relatively small number of slots, making it an attractive choice for fractional-slot concentrated winding configurations.

Slotting affects the air gap magnetic field in two ways. First, it reduces the total magnetic flux linkage per pole. This effect is accounted for by introducing the well-known Carter coefficient $K_{c}$ [11], [12]. Second, slotting affects the distribution of the flux in both the air gap and in the magnets. This effect is accounted for by introducing a relative permeance function $\lambda_{\mathrm{ag}}$ that can be represented as a Fourier series [11]

$$
\lambda_{\mathrm{ag}}\left(\theta_{s}, r_{g}\right)=\sum_{n=0}^{\infty} \lambda_{n}\left(r_{g}\right) \cos \left(n S \theta_{s}\right)
$$

where $\lambda_{n}$ is the $n$th harmonic component of the relative permeance function, and $S$ is the number of slots.

For a slotted machine, the magnetic flux density in the air gap with the stator windings open-circuited is expressed as

$$
B_{\text {open-circuit }}\left(\theta, r_{g}\right)=\lambda_{\text {ag }}\left(\theta_{s}, r_{g}\right) B_{\text {mag }}\left(\theta_{s}, \theta_{r}, r_{g}\right)[T]
$$

\section{B. Cogging Torque}

The task of calculating and minimizing the cogging torque in PM machines is typically accomplished using either the virtual work or Maxwell stress tensor methods. The model chosen for this analysis [13] uses the Fourier representation of the air gap magnetic field produced by the magnets and the relative permeance functions discussed in the preceding section. The energy stored in the air gap $W_{\text {airgap }}$ (in Joules) can be calculated as a function of the rotor angle $\theta_{r}$ as follows:

$$
\begin{aligned}
& W_{\text {airgap }}\left(\theta_{r}\right) \\
& =\frac{l_{\text {eff }}\left(r_{s}^{2}-r_{m}^{2}\right)}{4 \mu_{o}} \\
& \quad \times \int_{0}^{2 \pi} B_{\text {mag }}^{2}\left(\theta_{s}, \theta_{r}, r_{\text {gav }}\right) \lambda_{\text {ag }}^{2}\left(\theta_{s}, r_{\text {gav }}\right) d \theta_{s}[J]
\end{aligned}
$$

where leff is the machine active length $[\mathrm{m}], \mu_{0}$ is the permeability of air $[\mathrm{H} / \mathrm{m}], r_{m}$ is the outer radius of the magnets [m], and $r_{s}$ is the inner radius of the stator bore [m], and the airgap radius is set at $r_{g}=r_{\text {gav }} \equiv\left(r_{s}+r_{m}\right) / 2$. The roles of $r_{s}$ and $r_{m}$ are reversed in (5) for an external rotor. 
The cogging torque $T_{\mathrm{cog}}$ can be calculated as follows:

$$
\begin{aligned}
& T_{\operatorname{cog}}\left(\theta_{r}\right) \\
& \quad=-\frac{\partial W_{\text {airgap }}\left(\theta_{r}\right)}{\partial \theta_{r}} \\
& \quad=\frac{1}{4 \mu_{0}} l_{\text {eff }}\left(r_{s}^{2}-r_{m}^{2}\right) \sum_{n=1}^{\infty} n N B_{n N}^{2} \lambda_{n N}^{2} \sin \left(n N \theta_{r}\right)[\mathrm{Nm}]
\end{aligned}
$$

where $N$ is the least common multiple (LCM) of $2 p$ and $S$, and $B_{n N}^{2}$ and $\lambda_{n N}^{2}$ are the Fourier coefficients of $B_{\text {mag }}^{2}\left(\theta_{s}, \theta_{r}, r_{\text {gav }}\right)$ and $\lambda_{\text {ag }}^{2}\left(\theta_{s}, r_{\text {gav }}\right)$, respectively, for a period of $2 \pi / N$.

\section{Back-EMF Calculation}

The back-emf $e$ can be expressed in the form of a Fourier series [14]:

$$
\begin{aligned}
e & =\sum_{n} p \omega_{r} \Phi_{n} N_{s} K_{\mathrm{wn}} \sin \left(n p \theta_{r}\right) \\
& =\sum_{n} E_{n} \sin \left(n p \theta_{r}\right) \quad[V \mathrm{rms}]
\end{aligned}
$$

where $\omega_{r}\left(=d \theta_{r} / d t\right)$ is the rotor angular velocity [mech. $\left.\mathrm{rad} / \mathrm{s}\right]$, $N_{s}$ is the number of series winding turns, $K_{\mathrm{wn}}$ is the $n$th harmonic winding factor, $\theta_{r}$ is the angle between the axis of phase $A$ and the permanent magnet axis [mech. rad], and

$$
\Phi_{n}=2 r_{s} l_{\text {eff }} \lambda_{o}\left[B_{n}\left(r_{\text {gav }}\right)\right] \quad \text { [Webers-per-turn] }
$$

where $\lambda_{o}$ is the average value of the relative permeance function $\lambda_{\text {ag }}\left(\theta_{s}, r_{\text {gav }}\right)$.

The most challenging aspect of calculating the back-emf waveform is determining the various harmonic winding factors that result from the adoption of concentrated windings. There are several alternative methods for accomplishing this task, including some approaches that yield closed-form solutions [6], [15].

A preferred method for calculating the harmonic winding factors is to use the well-known winding function [16]. A baseline concentrated winding is first defined that has the same number of turns as the winding of interest but wound in a configuration with 1 slot/pole/phase and a winding pitch of $180 \mathrm{elec} \mathrm{deg}$. The $h$ th harmonic winding factor of the winding of interest $K_{w_{h}}$ can then be calculated as

$$
K_{w_{h}}=\frac{N_{h}}{N_{h \text { base }}}
$$

where $N_{h}$ is the amplitude of the $h$ th -order spatial harmonic component of the winding function for the winding of interest, and $N_{h \text { base }}$ is the amplitude of the $h$ th -order harmonic component of the winding function for the baseline $1 \mathrm{slot} / \mathrm{pole} / \mathrm{phase}$ winding.

\section{Resistance and Inductance Calculation}

1) Resistance Calculations: The resistance calculation is straightforward except for estimating an average length of the concentrated winding turns. The lengths of the winding end turns vary as the turns move further away from the tooth wall.

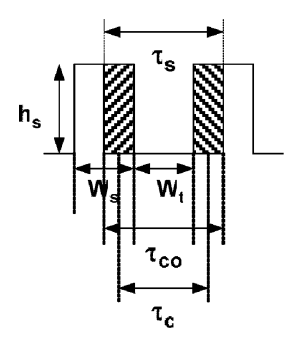

(a)

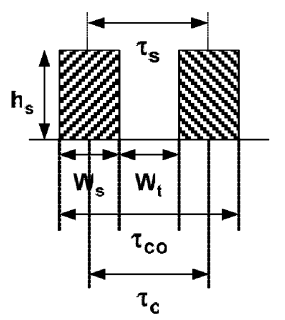

(b)

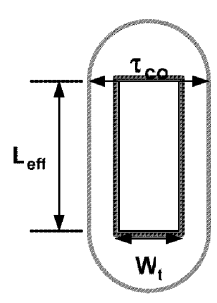

(c)
Fig. 3. Details of stator concentrated winding. (a) Double-layer winding coil. (b) Single-layer winding coil. (c) End turn configuration.

Fig. 3(a) and (b) shows the layouts of one coil in double-layer and single-layer windings, respectively. The geometric assumptions used in the end-turn length calculation are illustrated in Fig. 3(c). In particular, the innermost turn is assumed to have a straight end turn, while the outermost turn is assumed to have a semi-circular end turn with width $\tau_{\mathrm{co}}$, defined as follows:

$$
\begin{aligned}
& \tau_{\mathrm{co}}=\tau_{s} \text { in case of double-layer winding }[\mathrm{m}] \\
& \tau_{\mathrm{co}}=W_{s}+\tau_{s} \text { in case of single-layer winding }[\mathrm{m}]
\end{aligned}
$$

where $\tau_{s}$ is the slot pitch, and $W_{s}$ is the slot width (Fig. 3).

The average end turn length can be calculated as follows:

$$
\begin{aligned}
& l_{\text {end,min }} \approx W_{t}[m] \\
& l_{\text {end,max }} \approx \frac{\pi \tau_{\text {co }}}{2}[m] \\
& l_{\text {end,avg }}=\frac{l_{\text {end,min }}+l_{\text {end,max }}}{2}[m]
\end{aligned}
$$

where $W_{t}$ is the tooth width.

Finally, the average turn length can be calculated as

$$
l_{\text {turn }, \text { avg }}=2 * l_{\text {eff }}+2 * l_{\text {end,avg }}[m]
$$

2) Inductance Calculations: The machine inductances can be conveniently calculated using the winding functions [16]. For example, the phase self-inductance can be calculated as follows:

$$
L_{a a}=\frac{\mu_{0} r_{g} l_{\mathrm{eff}}}{g} \int_{0}^{2 \pi} N_{a}^{2}(\theta) d \theta[H]
$$

and the mutual inductance can be calculated as follows:

$$
L_{\mathrm{ab}}=\frac{\mu_{0} r_{g} l_{\mathrm{eff}}}{g} \int_{0}^{2 \pi} N_{a}(\theta) N_{b}(\theta) d \theta[H]
$$

where $N_{a}(\theta)$ and $N_{b}(\theta)$ are the winding functions of phases $a$ and $b$, respectively, $r_{g}$ is the air gap radius, and $g$ is the air gap length.

The inductance calculation using winding functions includes both the magnetizing inductance and the harmonic leakage inductance. Other components of the leakage inductance including slot leakage, end leakage, and zig-zag leakage can be calculated using classical equations that are well established in literature [12]. As the effective air gap becomes progressively larger, more accurate 2D models for evaluating the slot leakage inductance become necessary [17]-[19]. 


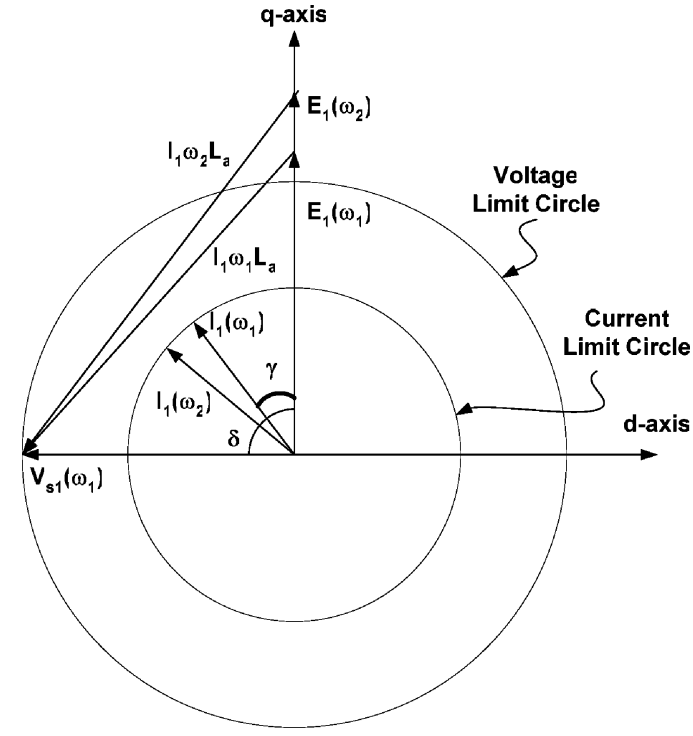

Fig. 4. Vector diagram showing conditions for operation of SPM machine above its base speed.

\section{E. Torque Calculation Above Corner Speed}

Above the corner speed, maximum torque can be extracted from the machine by allowing the current regulator to saturate so that the inverter operates in its six-step voltage excitation mode. In this case, the Fourier series representing the phase voltage can be written as follows:

$$
\begin{aligned}
V_{s}(t)= & \frac{2}{\pi} V_{\mathrm{dc}} \\
& \times\left[\cos \left(\omega_{e} t\right)+\frac{1}{5} \cos \left(5 \omega_{e} t\right)-\frac{1}{7} \cos \left(7 \omega_{e} t\right) \ldots\right]
\end{aligned}
$$

where $V_{s}(t)$ is the phase voltage [V], and $V_{\mathrm{dc}}$ is the dc bus voltage [V].

As a result, the excitation voltage can be considered as a superposition of balanced sinusoidal voltage excitation sets at each of the harmonic angular frequencies. The rms amplitude of the $k$ th harmonic phase voltage is

$$
\left|V_{s k}\right|=\frac{\sqrt{2}}{k \pi} V_{\mathrm{dc}}[\mathrm{Vrms}]
$$

where $k$ is any odd integer, excluding all triplen harmonics (i.e., $k=3 n$ ). The fundamental component and harmonic orders 7 , 13, etc., develop forward-rotating magnetic flux waves in the air gap, while the harmonic orders 5,11 , etc., produce reverserotating flux waves.

Equation (19) only determines the magnitude of the harmonic components of the supply voltage. Maximizing the machine torque without exceeding either the current or voltage limit requires proper adjustment of the excitation phase angle with respect to the rotor position. Since torque production is dominated by the fundamental component, maximum torque can be achieved if the torque angle $(\delta)$ associated with the fundamental voltage component is adjusted to $90^{\circ}$ elec. However, this condi-

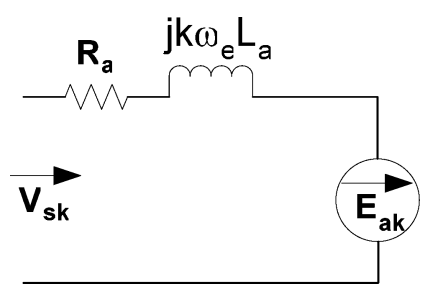

Fig. 5. Per-phase equivalent circuit of an SPM machine.

tion is subject to the constraint that the phase current must not exceed the rated current. If it does, the torque angle must be reduced until the rms current falls within the rated current limit.

The fundamental component vector diagram in Fig. 4 shows this operating condition with $\delta=90^{\circ}$ for two different operating speeds above the corner speed. The current angle $\gamma$ is defined as the angle between the $q$-axis (back-emf axis) and the current vector. It can be observed that the current vector gradually shifts towards the negative $d$-axis (magnet flux axis) as the rotor speed increases in order to counteract the magnet flux (i.e., flux weakening).

The amplitudes and angles of all of the current components in the Fourier series can be calculated by applying individual voltage frequency components from (19) to the machine equivalent circuit in Fig. 5. The angle of the fundamental component of the supply voltage with respect to the back-emf (i.e., torque angle $\delta$ ) is set to be $90^{\circ}$ elec as described above in the absence of current-limit activation. This action uniquely determines the angles between each of the higher-order harmonic supply voltage components and the corresponding back-emf voltage component (if present). The resulting current components can then be summed to synthesize the total phase current waveforms.

More specifically, the $k$ th harmonic component of the stator current can be calculated as

$$
\vec{I}_{k}=\frac{\vec{V}_{s k}-\vec{E}_{a k}}{R_{a}+j k \omega_{e} L_{a}}[\text { Arms }]
$$

where $V_{s k}$ is the $k$ th harmonic phase supply voltage component [Vrms] from (19), $R_{a}$ is the phase armature resistance [Ohm], $L_{a}$ is the phase inductance [H], and $E_{a k}$ is the $k$ th frequency component of the back-emf phase voltage [Vrms]. The total rms value of the phase current $I_{a_{\mathrm{rms}}}$ can then be calculated as

$$
I_{a \mathrm{rms}}=\sqrt{\sum_{k=1,5,7, \ldots}\left|\vec{I}_{k}\right|^{2}}[\text { Arms }]
$$

If $I_{a_{\mathrm{rms}}}$ exceeds the rated rms current, the torque angle $\delta$ is reduced by $1^{\circ}$ (or any other chosen step angle) and the whole process is repeated again until $I_{a_{\mathrm{rms}}}$ falls within the rated current limit as shown in the flowchart in Fig. 6.

When $I_{a_{\mathrm{rms}}}$ falls within the rated rms current limit, the torque can be calculated using the back-emf and phase current waveforms. The back-emf waveform is calculated using (7) while the phase current waveform can be reconstructed using the current harmonic components calculated using (20). Once the waveforms for one of the phases is determined, the waveforms for the other two phases are assumed to be the same (i.e., balanced excitation) but progressively time-shifted by 120 elec. degrees, 


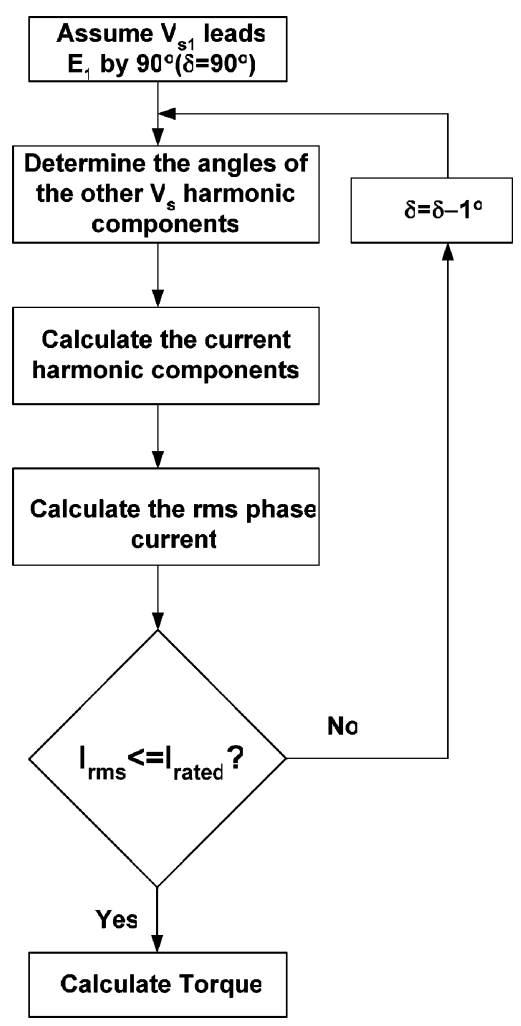

Fig. 6. Flowchart showing algorithm for calculating the torque above the corner speed.

leading to the following expression for torque $\mathrm{T}$ :

$$
T=\frac{e_{a} i_{a}+e_{b} i_{b}+e_{c} i_{c}}{\omega_{r}}[N m]
$$

where $e_{a}, e_{b}$, and $e_{c}$ are the instantaneous phase back-emfs [V], and $i_{a}, i_{b}$ and $i_{c}$ are the instantaneous phase currents [A].

While (22) gives the instantaneous torque including the ripple torque, the average value of (22) is represented as $T_{\text {avg }}$.

\section{F. Machine Losses}

There are four major contributors to the machine losses consisting of stator winding copper losses, core losses in the stator and rotor iron, losses in the rotor magnets, and losses in the magnet retaining sleeve (if present). Techniques exist for calculating each of the four loss components [20]-[22].

In particular, predicting the magnet losses presents special challenges because of the impact of the significant spatial harmonic components in the airgap magnetic flux density distribution caused by the concentrated windings.

In view of the space required to adequately address this important topic, loss calculations for the fractional-slot concentrated winding PM machine and their impact on machine efficiency are addressed in a separate paper [23]

\section{ANALYTICAL Results}

The predicted performance characteristics of a $6 \mathrm{~kW}$, 36-slot/42-pole SPM machine design [3] using fractional-slot concentrated windings are presented here to illustrate the ap-

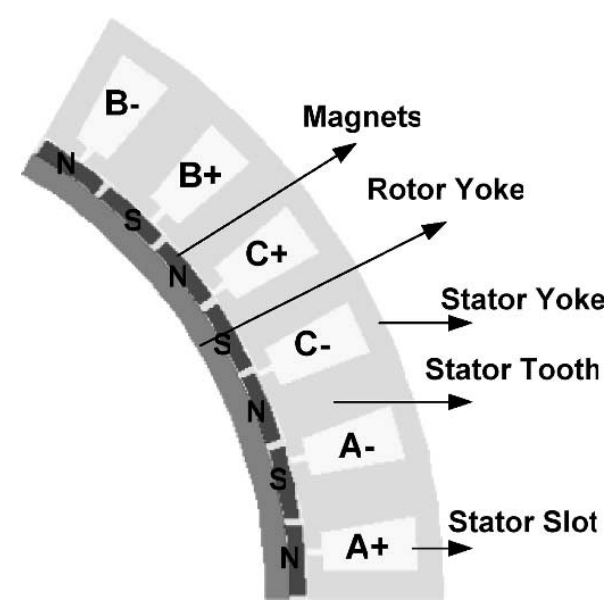

Fig. 7. Basic repeating unit of 36-slot/42-pole, 6-kW SPM machine consisting of six stator slots and seven poles.

TABLE I

Stator SPECIFICATIONS OF THE 36-SLOT/42-Pole Design

\begin{tabular}{|c|c|c|c|}
\hline Number of slots & 36 & Number of poles & 42 \\
\hline Number of phases & 3 & Slots/pole/phase & $2 / 7$ \\
\hline Series turns & 26 & Number of turns/coil & 26 \\
\hline Number of coils & 6 & Number of parallel paths & 6 \\
\hline Outer diameter & $272[\mathrm{~mm}]$ & Active length & $60[\mathrm{~mm}]$ \\
\hline Total length & $73[\mathrm{~mm}]$ & Slot fill factor & $70 \%$ \\
\hline Slot opening width & $2[\mathrm{~mm}]$ & Slot bottom width & $7.6[\mathrm{~mm}]$ \\
\hline Slot top width & $11.4[\mathrm{~mm}]$ & Slot opening height & $3[\mathrm{~mm}]$ \\
\hline Slot height & $18.9[\mathrm{~mm}]$ & Back iron thickness & $5[\mathrm{~mm}]$ \\
\hline Tooth width & $11.4[\mathrm{~mm}]$ & Phase resistance & $0.0032[\Omega]$ \\
\hline
\end{tabular}

TABLE II

ROTOR SPECIFICATIONS OF THE 36-SLOT/42-POLE DESIGN

\begin{tabular}{|c|c|c|c|}
\hline Rotor outer radius & $104.7[\mathrm{~mm}]$ & Magnets outer radius & $107.9[\mathrm{~mm}]$ \\
\hline Inner radius & $99.7[\mathrm{~mm}]$ & Air gap length & $0.635[\mathrm{~mm}]$ \\
\hline Magnet thickness & $3.2[\mathrm{~mm}]$ & Magnet span & $7.7^{\circ}[\mathrm{mech}]$ \\
\hline
\end{tabular}

TABLE III

INDUCTANCES OF THE 36-SLOT/42-POLE DESIGN

\begin{tabular}{|c|c|c|c|}
\hline $\begin{array}{c}\text { Self inductance } \\
\text { (including harmonic } \\
\text { leakage) }\end{array}$ & $43.75[\mu \mathrm{H}]$ & $\begin{array}{c}\text { Mutual inductance } \\
\text { (including harmonic } \\
\text { leakage) }\end{array}$ & $\sim 0$ \\
\hline $\begin{array}{c}\text { Self slot leakage } \\
\text { inductance }\end{array}$ & $43.38[\mu \mathrm{H}]$ & $\begin{array}{c}\text { Mutual slot leakage } \\
\text { inductance }\end{array}$ & $\sim 0$ \\
\hline Net self inductance & $87.13[\mu \mathrm{H}]$ & Net mutual inductance & $\sim 0$ \\
\hline
\end{tabular}

plication of the analytical methods described in the preceding sections. This machine is designed for excitation from a $42 \mathrm{Vdc}$ bus in an automotive application.

The basic building block of this machine is shown in Fig. 7 . Key stator parameters and dimensions are presented in Table I.

The rotor and magnet dimensions are presented in Table II. The various inductance components are included in Table III. The self- and mutual inductance components including harmonic leakage have been calculated using (16) and (17). The slot leakage inductance components have been calculated using the formulae presented in [12]. 
TABLE IV

FIELD SPECIFICATIONS OF THE 36-SLOT/42-POLE SPM MACHINE DESIGN

\begin{tabular}{|c|c|c|c|}
\hline Magnet remanence & 0.9 [Tesla] & $\begin{array}{c}\text { Magnet relative } \\
\text { permeability }\end{array}$ & 1.05 \\
\hline $\begin{array}{c}\text { RMS PM flux } \\
\text { linkage } \boldsymbol{\Psi}_{m}\end{array}$ & $9.9[\mathrm{mWeber}]$ & $\begin{array}{c}\text { RMS c/c current } \\
\boldsymbol{I}_{\boldsymbol{c h}} \boldsymbol{=} \boldsymbol{\Psi}_{\boldsymbol{m}} / \boldsymbol{L}_{\boldsymbol{d}}\end{array}$ & $\begin{array}{c}113.25 \\
{[\mathrm{Amps}]}\end{array}$ \\
\hline RMS rated current & $110[\mathrm{Amps}]$ & $\begin{array}{c}\text { Field-Weakening } \\
\text { index } \boldsymbol{I}_{\boldsymbol{c h}} / \boldsymbol{I}_{r}\end{array}$ & 1.03 \\
\hline Current density & $3.8\left[\mathrm{~A} / \mathrm{mm}^{2}\right]$ & Air gap shear stress & $\begin{array}{c}2.24[\mathrm{psi}] \\
15.4[\mathrm{kPa}]\end{array}$ \\
\hline \multicolumn{4}{|l}{} \\
(Note: All I and $\Psi$ variables are rms quantities).
\end{tabular}

TABLE V

BREAKDOWN OF MATERIAL MASS OF THE 36-SLOT/42-POLE SPM MACHINE DESIGN

\begin{tabular}{|c|c|c|c|}
\hline Copper mass & $3.3[\mathrm{~kg}]$ & Iron mass & $7.1[\mathrm{~kg}]$ \\
\hline Magnet mass & $0.87[\mathrm{~kg}]$ & Total mass & $11.27[\mathrm{~kg}]$ \\
\hline
\end{tabular}

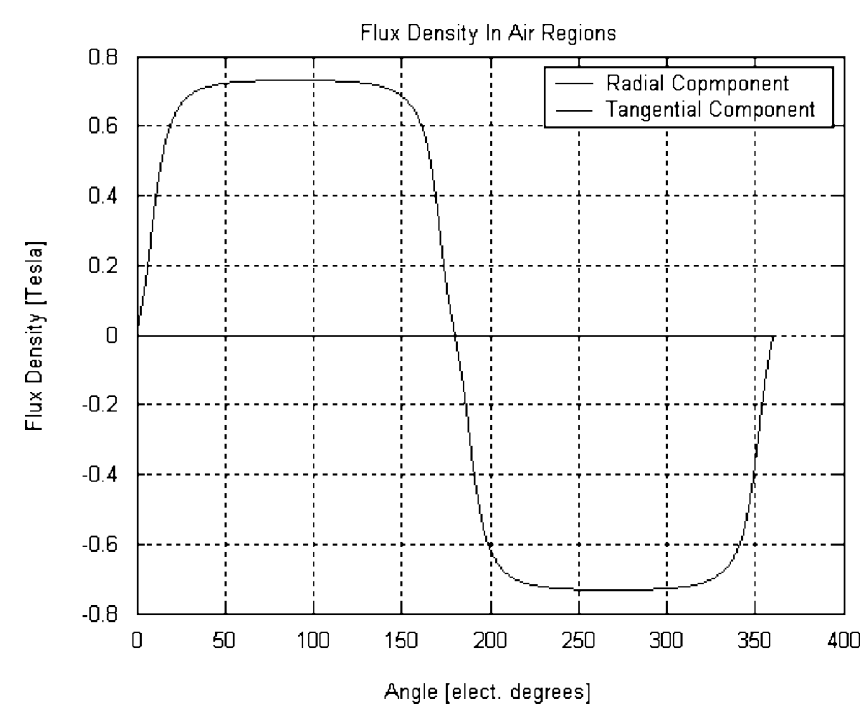

Fig. 8. Predicted air gap flux density produced at the stator bore by the magnets assuming slotless machine.

The various magnetic field specifications as well as the machine current ratings are presented in Table IV. The magnets used are sintered Neodynium-Iron-Boron $(\mathrm{NdFeB})$ magnets with a remanent flux density $B_{r}$ of $0.9 \mathrm{~T}$ and a relative permeability $\mu_{r}$ of 1.05 . Table entries show that this design has a field-weakening index value very close to unity, indicating optimal flux-weakening as previously mentioned.

Table $\mathrm{V}$ presents the breakdown of the machine stator and rotor mass into its three major material components.

The predicted air gap magnetic field produced by the magnets over one pole-pair at the stator bore assuming a slotless machine is shown in Fig. 8. The calculated relative permeance function for one rotor position is shown in Fig. 9 and the resulting air gap field produced by the magnets taking the slotting effect into consideration is shown in Fig. 10.

Fig. 10 shows that the effect of the slots is significant at the stator bore. This slot effect gradually diminishes as one moves

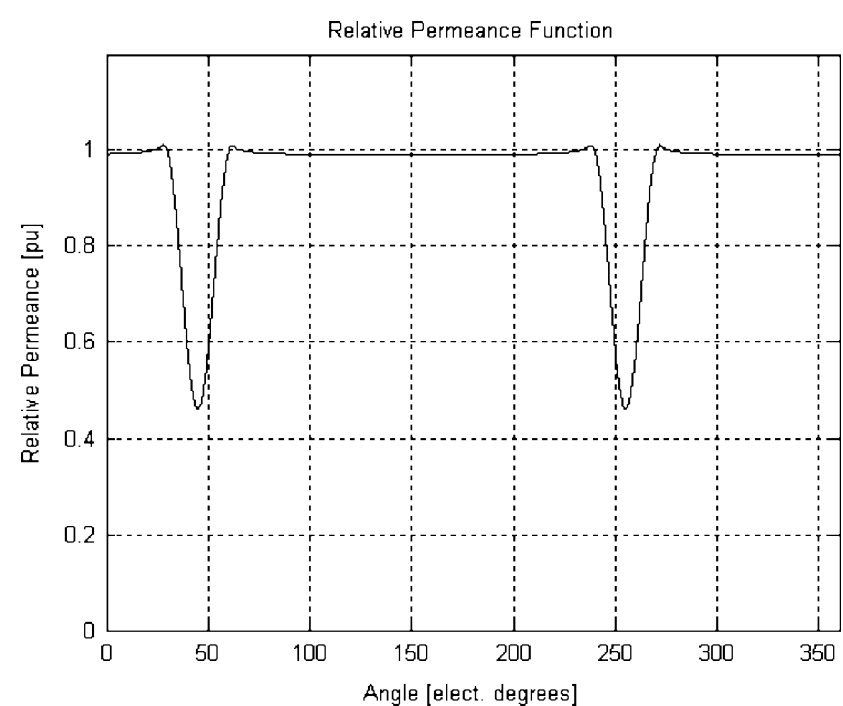

Fig. 9. Predicted relative permeance function $\lambda_{\mathrm{ag}}$ at the stator bore.

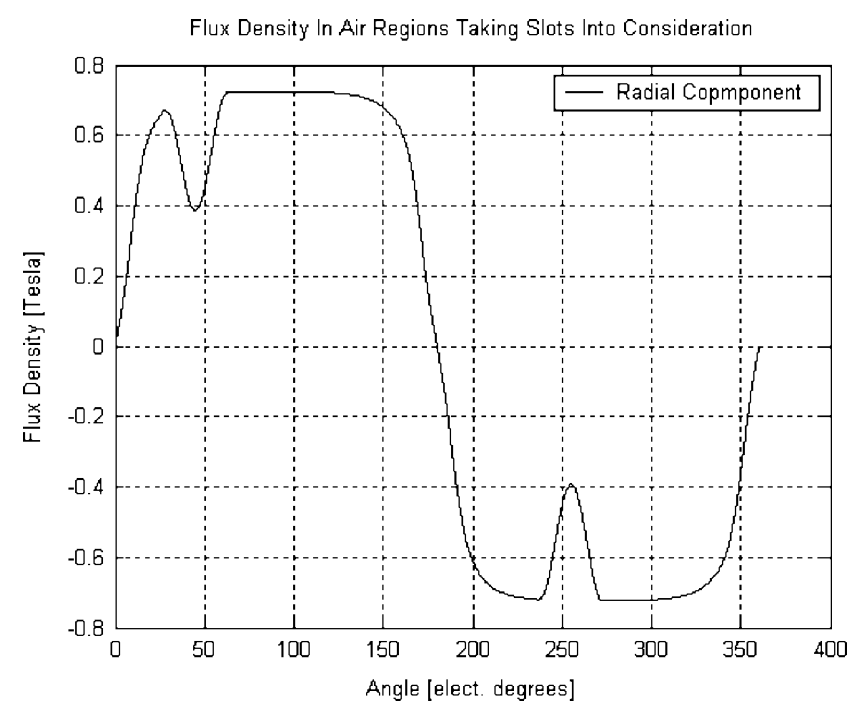

Fig. 10. Predicted air gap flux density produced by the magnets at the stator bore taking slotting effect into consideration.

radially from the stator bore towards the rotor bore, manifesting itself as shallower dips in the air gap field.

One period of the calculated cogging torque is shown in Fig. 11. The peak-to-peak cogging torque is in the vicinity of $1 \mathrm{Nm}$, corresponding to approximately $1.56 \%$ of the machine rated torque. This low cogging torque amplitude is expected due to the high value of the least common multiple (LCM) of the number of poles and the number of slots (252 in this case) that determines the cogging torque frequency [24].

The three phase-to-neutral back-emf waveforms at $600 \mathrm{r} / \mathrm{min}$ are shown in Fig. 12. The back-emf harmonic spectrum shows [3] that only the fundamental and 3rd harmonic components are significant while the other higher-order harmonics are negligible. The line-to-line back-emf waveforms look very sinusoidal since the triplen harmonics cancel in the line-to-line voltages.

Fig. 13 shows the predicted torque waveforms resulting from rated sinusoidal current excitation in the constant-torque range 


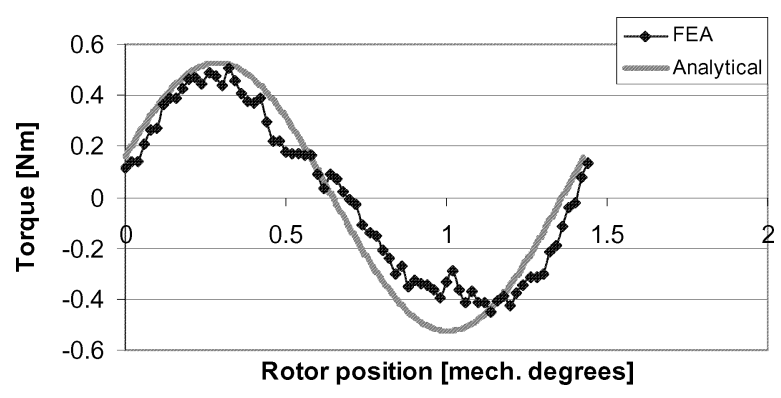

Fig. 11. Predicted cogging torque for the 36-slot/42-pole SPM machine, with a period of 1.43 mech deg. using both the analytical model and FEA.

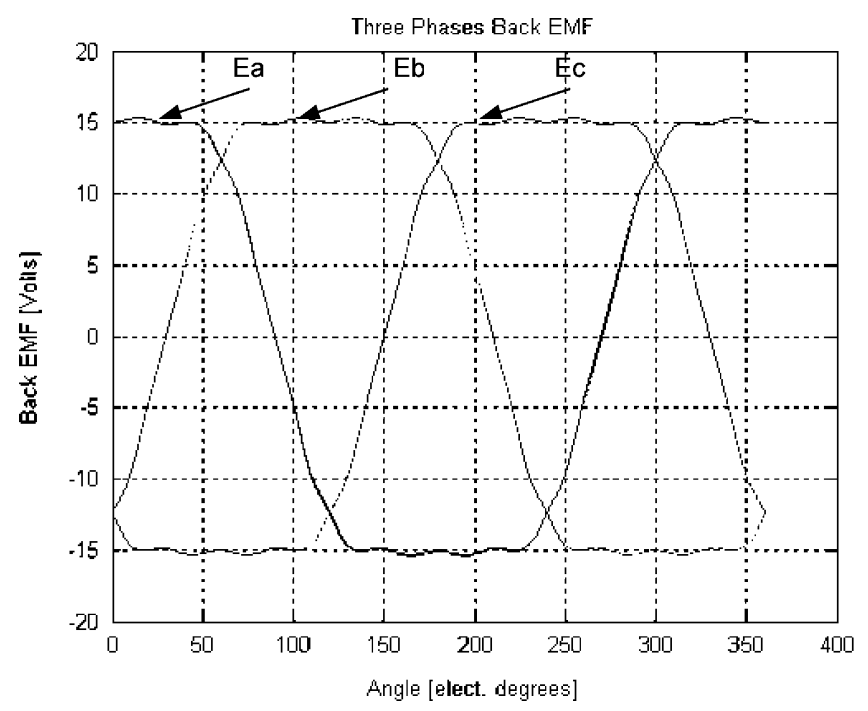

Fig. 12. Predicted phase-to-neutral back-emf waveforms at $600 \mathrm{r} / \mathrm{min}$.

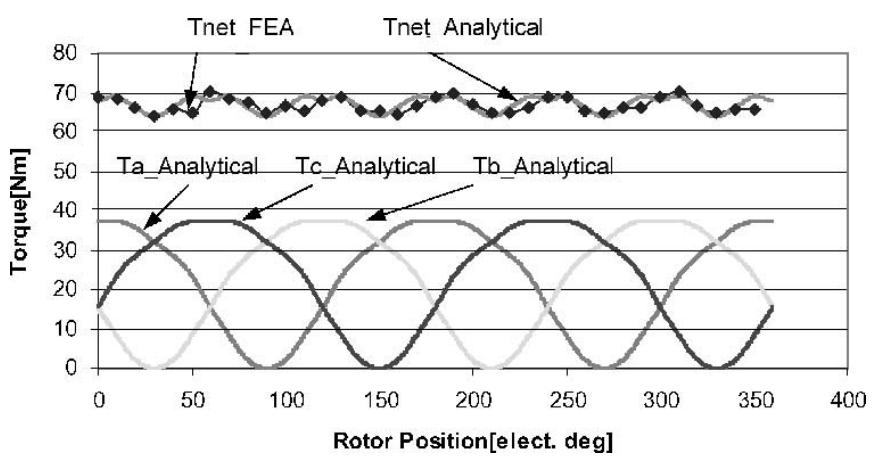

Fig. 13. Predicted instantaneous phase torque and total torque waveforms using closed-form analysis and the predicted total torque using FEA with sinusoidal current excitation $\left(I_{a \mathrm{rms}}=110\right.$ Arms $)$ at $500 \mathrm{r} / \mathrm{min}$.

below base speed at $500 \mathrm{r} / \mathrm{min}$. In this regime, the stator current vector is entirely oriented along the $q$-axis (i.e., no flux weakening). The calculated torque contributed by each of the three individual phases is shown in Fig. 13 along with the total torque.

As in the case of the line-to-line back-emf waveforms, the triplen harmonics do not contribute to torque production with balanced three-phase sinusoidal current excitation (i.e., zero neutral current). With rated phase current, the predicted peakto-peak ripple torque is $5.2 \mathrm{Nm}$, corresponding to $7.75 \%$ of the

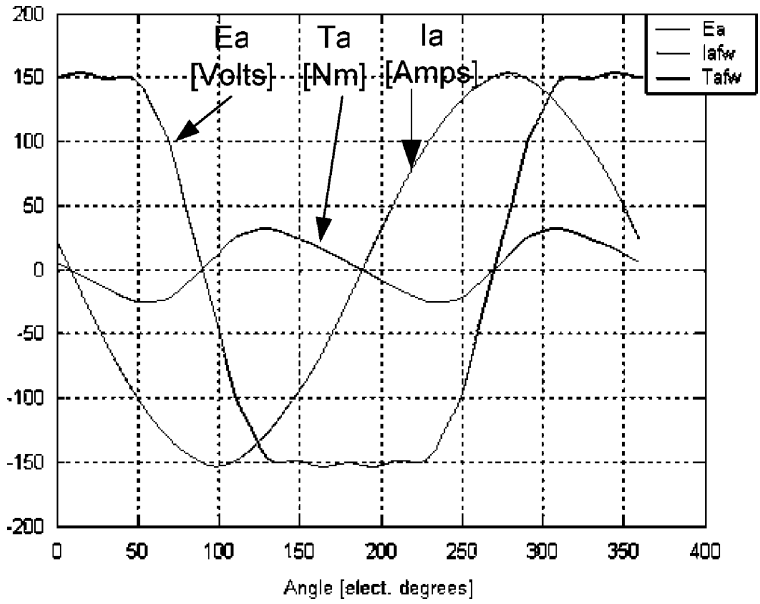

Fig. 14. Predicted phase current, back-emf, and contributed phase torque waveforms at $6000 \mathrm{r} / \mathrm{min}$ in six-step excitation mode.

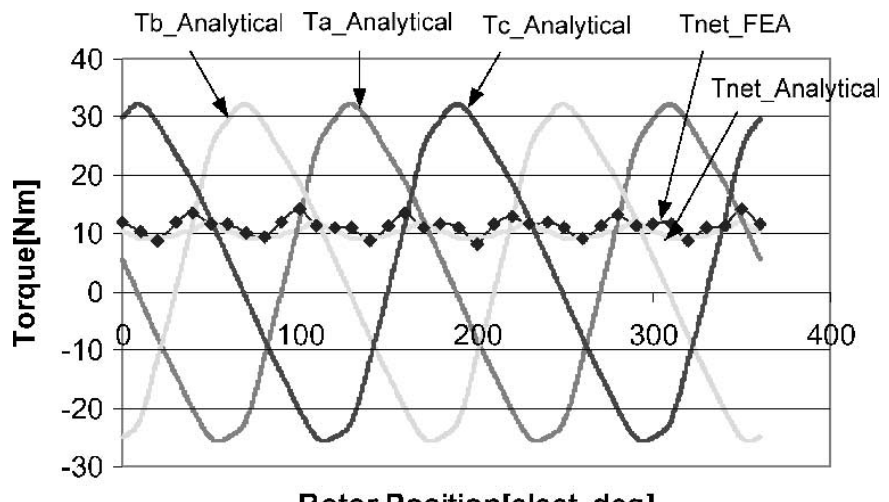

Rotor Position[elect. deg]

Fig. 15. Predicted instantaneous phase torque and total torque waveforms using closed-form analysis with six-step voltage excitation at $6000 \mathrm{r} / \mathrm{min}$ and predicted total torque using FEA for sinusoidal excitation at $\left(I_{a \mathrm{rms}}=107\right.$ Amps) and $\gamma=81.5^{\circ}$ at $6000 \mathrm{r} / \mathrm{min}$.

average torque $(67.1 \mathrm{Nm})$. It is possible to use programmed current profiling techniques to further reduce the ripple torque [25], [26].

Fig. 14 shows the predicted phase current, back-emf, and phase torque for operation at the maximum rotor speed of $6000 \mathrm{r} / \mathrm{min}$. Since this speed is above the corner speed, the current regulator is saturated and the machine is excited by six-step voltage waveforms for this operating condition.

The phase current in Fig. 14 leads the back-emf waveform by a large angle approaching 90 elec deg, corresponding to deep flux weakening. That is, the majority of the stator current is oriented along the negative $d$-axis to counteract the magnet flux at this high speed, thereby reducing the terminal voltage.

The predicted torque waveforms for this operating point at 6000 r/min are provided in Fig. 15. Under these flux-weakening conditions, the average torque is much lower than the value for operation at $500 \mathrm{r} / \mathrm{min}$ in Fig. 13, an expected result for constantpower operation. The amplitude of the ripple torque is a larger percentage of the average torque at $6000 \mathrm{r} / \mathrm{min}$ compared to $500 \mathrm{r} / \mathrm{min}$, but the rotor inertia acts as effective mechanical filter to minimize the resulting speed ripple at such high speed. 


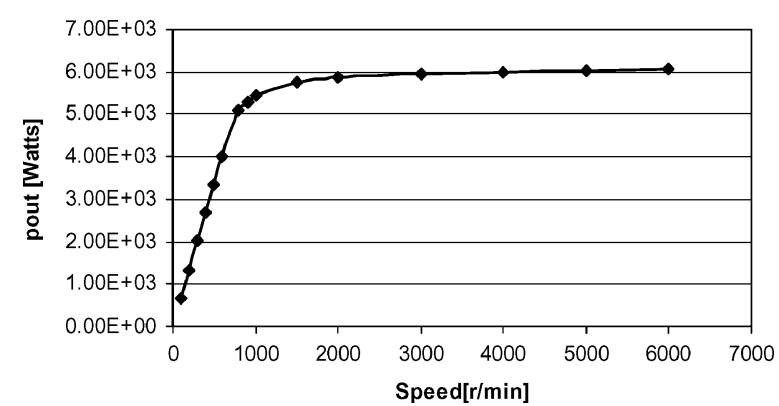

Fig. 16. Predicted power-vs-speed envelope for the 36-slot/42-pole SPM machine design.

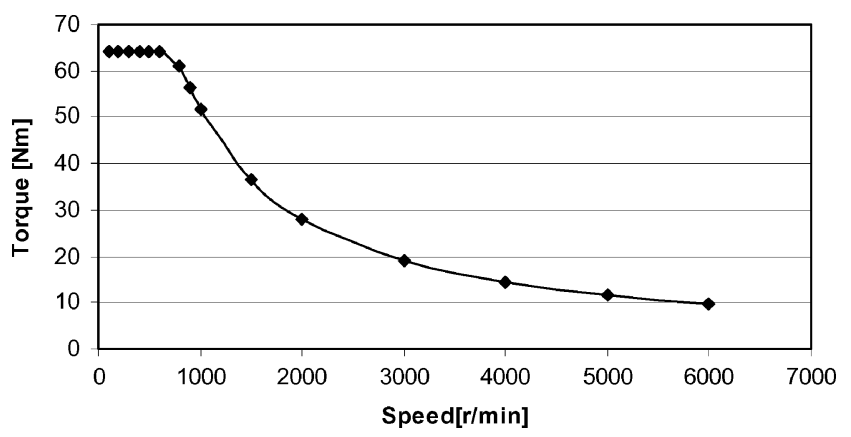

Fig. 17. Predicted torque-vs-speed envelope for the 36-slot/42-pole SPM machine design.

It is interesting to note that the predicted phase current waveform at $6000 \mathrm{r} / \mathrm{min}$ is almost perfectly sinusoidal despite the presence of the six-step voltage harmonics. The inductive impedance of the machine serves to effectively filter these harmonics at high speed. In contrast to this harmonic filtering, the fundamental current component is maintained at its rated value by adjusting the torque angle between the supply voltage and the back-emf for flux-weakening operation.

Entries in Table I show that this machine satisfies the conditions for optimal flux weakening since the machine's characteristic current is almost the same as the rated current. In order to verify the optimal flux weakening of this machine, the analytical model was used to calculate the machine's predicted performance envelope from 0 to $6000 \mathrm{r} / \mathrm{min}$. The predicted power vs. speed envelope of the machine is shown in Fig. 16, and the corresponding torque vs. speed envelope is shown in Fig. 17. These curves predict that the machine can meet its desired constantpower speed ratio value of 10 .

\section{Finite Element Analysis Results}

The analytical results presented in the previous section have been verified using FEA. Two FEA packages have been used: MagNet 2D by Infolytica and Maxwell 2D by Ansoft. Although magnetic saturation effects are generally not very significant in SPM machines, they are specifically included in this finite element analysis.

It is only necessary to analyze one pole or one pole-pair of a machine with integral-slot windings by taking advantage of the design symmetry. This approach saves considerable com-

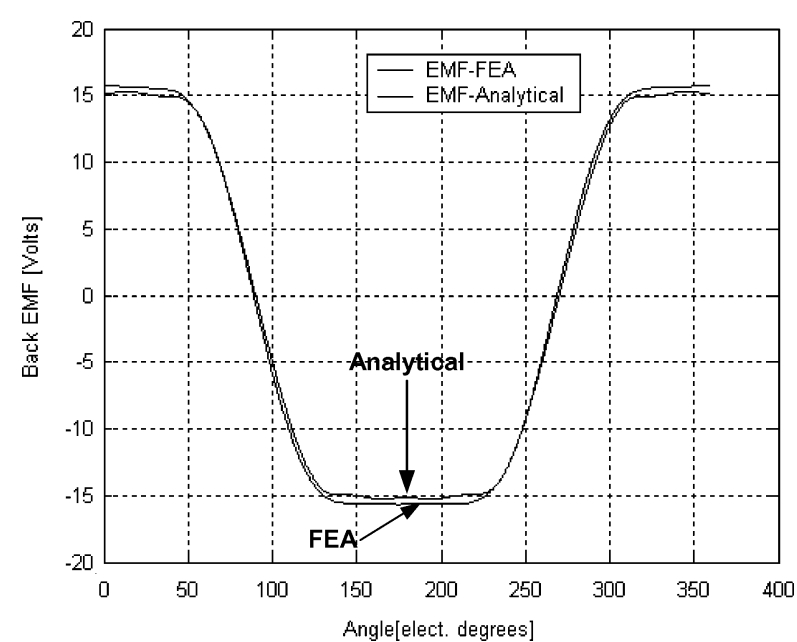

Fig. 18. Comparison of predicted back-emf waveforms at $600 \mathrm{r} / \mathrm{min}$ using closed-form analysis and FEA.

putation time compared to modeling the whole machine. This simplification cannot be used when fractional-slot concentrated windings are used. For the 36-slots/42-pole machine design under consideration here, the basic repeating unit that must be simulated is six slots and seven poles, as shown in Fig. 7.

Current excitation has been used instead of voltage excitation to save FEA simulation time. A series of static solutions as well as transient solutions have been used to verify the results. Second-order elements have been used in order to improve accuracy, especially in the case of cogging torque calculations. The air gap has been divided into three layers, and 20 peripheral mesh elements per cogging period have been used in each layer.

The predicted back-emf waveforms at $600 \mathrm{r} / \mathrm{min}$ for both closed-form analysis and FEA are compared in Fig. 18, demonstrating very good agreement. (The predicted waveforms are nearly identical using MagNet or Maxwell 2D.) The difference between the fundamental rms magnet flux linkage predicted using closed-form analysis and FEA is only $0.47 \%$. The magnet flux linkage predicted by the analytical calculations is $9.95 \mathrm{mWb}$ rms, while the magnet flux linkage predicted by FEA is $9.90 \mathrm{mWb}$ rms.

The calculated phase winding inductance from the closedform analysis has also been verified using FEA (both MagNet and Maxwell 2D). The machine phase inductance (including slot leakage) predicted by the analytical calculations is $87.13 \mu \mathrm{H}$, while the corresponding value predicted by FEA is $85 \mu \mathrm{H}$. This difference of only $2.5 \%$ is quite reasonable, taking into consideration the difficulty of accurately predicting the slot leakage inductance.

Using FEA (MagNet 2D), the predicted total torque at $500 \mathrm{r} / \mathrm{min}$ with rated sinusoidal current (110 Arms) is shown in Fig. 13. The predicted total torque waveforms using closedform analysis and FEA match quite well. The predicted average torque for this waveform is $66.8 \mathrm{Nm}$ using FEA compared to 67.1 Nm predicted by the closed-form analysis, a difference of $0.5 \%$. The peak-to-peak torque ripple predicted by FEA is approx. $6.4 \mathrm{Nm}(9.6 \%$ of the average torque), while the model 
predicts $5.2 \mathrm{Nm}$ (7.75\% of the average torque). These differences are quite modest, and both techniques predict that the machine will be capable of delivering $4 \mathrm{~kW}$ mechanical output power at $600 \mathrm{r} / \mathrm{min}$ as required by the specifications.

The FEA-predicted total torque waveform at $6000 \mathrm{r} / \mathrm{min}$ with 107 Amps rms and a current vector angle $\gamma$ of $81.5^{\circ}$ is shown in Fig. 15 (MagNet 2D). Here again, the match in the torque waveshapes for closed-form analysis and FEA is quite good. The average torque for this waveform is $11.34 \mathrm{Nm}$. The predicted average torque using closed-form analysis for this same operating condition is $10.3 \mathrm{Nm}$, a difference of $9 \%$. The predicted torque ripple from the FEA results is approx. $5 \mathrm{Nm}(44 \%$ of average torque) while the corresponding value using closedform analysis is approx. $2.9 \mathrm{Nm}$ (29\% of average torque). It should be noted that the FEA results are based on sinusoidal current excitation and do not account for the current harmonics that result from six-step voltage excitation.

Both analysis techniques predict that the machine will be capable of producing at least $6 \mathrm{~kW}$ output power at $6000 \mathrm{r} / \mathrm{min}$, meeting the requirement for a wide constant-power speed range.

One period of the predicted cogging torque waveform using FEA (MagNet 2D) is included in Fig. 11. Estimating the cogging torque for this machine design using FEA is a very challenging computational task. As described earlier, the cogging torque has a very high spatial frequency with a period of only 1.43 mech. degrees. Smooth, accurate prediction of the cogging torque requires a high number of mesh elements within this very small angle along the air gap, causing the computational time to become excessive. As a result, the cogging torque waveform predicted using FEA is not very smooth. Nevertheless, the agreement between the predicted amplitudes of the cogging torque using the two analytical techniques is quite good, with both predicting peak-to-peak amplitudes of approx. $1 \mathrm{Nm}$.

\section{CONCLUSION}

A closed-form analytical model has been presented that can analyze surface PM machines designed with fractional-slot concentrated windings. The model is capable of analyzing the machine below base speed (constant-torque region) and above it (flux-weakening region). Special features of the fractional-slot concentrated windings are taken into account, including stator slot effects. The technique is sufficiently general to handle a wide range of concentrated winding configurations, providing a fast and reliable method to analyze and compare candidate machine designs.

In addition to predicting the machine parameters and backemf waveforms, this analytical technique is also capable of evaluating the average torque, ripple torque, and the cogging torque. Extensions of this model not presented in this paper have also been developed to predict the machine losses and efficiency [23].

Results of applying this technique to a $6 \mathrm{~kW} 36$-slot/42-pole SPM machine have been presented, demonstrating that attractive performance features can be achieved with such machines including wide speed ranges of constant-power operation. Results of the closed-form analysis have been verified using finite element analysis, exhibiting good agreement for key machine parameters and performance metrics.

\section{ACKNOWLEDGMENT}

The authors acknowledge the Wisconsin Electric Machines and Power Electronics Consortium (WEMPEC) for use of its facilities.

\section{REFERENCES}

[1] W. Soong and T. J. E. Miller, "Field weakening performance of brushless synchronous AC motor drives," in Proc. IEE-Electric Power Applications, vol. 141 , no. 6 , Nov. 1994 , pp. 331-340.

[2] R. F. Schiferl and T. A. Lipo, "Power capability of salient pole permanent magnet synchronous motor in variable speed drive applications," IEEE Trans. Ind. Appl., vol. 26, pp. 115-123, Jan.-Feb. 1990.

[3] A. M. EL-Refaie and T. M. Jahns, "Optimal flux weakening in surface PM machines using concentrated windings," IEEE Trans. Ind. Appl., vol. 41, no. 3, pp. 790-800, May/Jun. 2005.

[4] R. H. Park, "Two-reaction theory of synchronous machines generalized method of analysis-Part I," Trans. AIEE, pp. 716-730, Jul. 1929.

[5] J. Cros and P. Viarouge, "Synthesis of high performance PM motors with concentrated windings," IEEE Trans. Energy Conv., vol. 17, no. 2, pp. 248-253, Jun. 2002.

[6] F. Magnussen and C. Sadarangani, "Winding factors and joule losses of permanent magnet machines with concentrated windings," in Proc. 2003 IEEE Intl Elec. Machines \& Drives Conf. (IEMDC'03), vol. 1, Madison, WI, Jun. 2003, pp. 333-339.

[7] J. Cros, J. R. Figueroa, and P. Viarouge, "BLDC motors with surface mounted PM rotor for wide constant power operation," in Rec. 2003 IEEE Industry Applications Society Annual Meeting, vol. 3, Salt Lake City, UT, Oct. 2003, pp. 1933-1940.

[8] F. Magnussen, P. Thelin, and C. Sadarangani, "Performance evaluation of permanent magnet synchronous machines with concentrated and distributed windings including the effect of field weakening," in Proc. 2nd IEE Int. Conf. Power Electronics, Machines and Drives (PEMD 2004), vol. 2, Edinburgh, U.K., Mar./Apr. 2004, pp. 679-685.

[9] Z. Q. Zhu "Electromagnetic Performance of Brushless Permanent Magnet DC motors, with Particular Reference to Noise and Vibration," Ph.D dissertation, Univ. Sheffield, Sheffield, U.K., 1991.

[10] Z. Q. Zhu, D. Howe, and C. C. Chan, "Improved analytical model for predicting the magnetic field distribution in brushless permanent-magnet machines," IEEE Trans. Magn., vol. 38, no. 1, pp. 229-238, Jan. 2002.

[11] Z. Q. Zhu, D. Howe, E. Bolte, and B. Ackermann, "Instantaneous magnetic field distribution in brushless permanent magnet dc motors, part III: Effect of stator slotting," IEEE Trans. Magn., vol. 29, no. 1, pp. 143-151, Jan. 1993.

[12] T. A. Lipo, Introduction to AC Machine Design. Wisconsin Power Electronics Research Center, Univ. Wisconsin, Madison, 1996.

[13] S. Hwang, J. Eom, Y. Jung, D. Lee, and B. Kang, "Various design techniques to reduce cogging torque by controlling energy variation in permanent magnet motors," IEEE Trans. Magn., vol. 37, no. 4, pp. 2806-2809, Jul. 2001

[14] Z. Q. Zhu, D. Howe, E. Bolte, and B. Ackermann, "Instantaneous magnetic field distribution in brushless permanent magnet dc motors, part IV: Magnetic field on load," IEEE Trans. Magn., vol. 29, no. 1, pp. 152-158, Jan. 1993.

[15] M. M. Liwschitz, "Distribution factors and pitch factors of the harmonics of a fractional-slot winding," AIEE Trans., vol. 62, pp. 664-666, Oct. 1943.

[16] D. W. Novotny and T. A. Lipo, Vector Control and Dynamics of AC Drives Oxford, U.K.: Calderon, 1998.

[17] Z. Q. Zhu, D. Howe, and T. S. Birch, "Calculation of winding inductances of brushless motors with surface-mounted permanent magnets," in Proc. Int. Conf. Electrical Machines (ICEM), Paris, France, 1994, pp. 327-332.

[18] Z. Q. Zhu and D. Howe, "Winding inductances of brushless machines with surface-mounted magnets," in Proc. Int. Elect. Machines and Drives Conf. (IEMDC), May 1997, pp. WB2/2.1-WB2/2.3.

[19] Z. Q. Zhu, D. Howe, and J. K. Mitchell, "Magnetic field analysis and inductances of brushless dc machines with surface-mounted magnets and non-overlapping stator windings," IEEE Trans. Magn., vol. 31, no. 3, pp. 2115-2118, May 1995. 
[20] C. Mi, G. R. Slemon, and R. Bonert, "Modeling of iron losses of permanent-magnet synchronous motors," IEEE Trans. Ind. Appl., vol. 39, no. 3, pp. 734-742, May/Jun. 2003.

[21] I. Takahashi, T. Koganezawa, G. Su, and K. Ohyama, “A super high speed PM motor drive system by a quasi-current source inverter," IEEE Trans. Ind. Appl., vol. 30, pp. 683-690, May/Jun. 1994.

[22] K. Atallah, D. Howe, P. H. Mellor, and D. A. Stone, "Rotor loss in permanent-magnet brushless AC machines," IEEE Trans. Ind. Appl., vol. 36, pp. 1612-1618, Nov./Dec. 2000.

[23] A. M. EL-Refaie and T. M. Jahns, "Comparison of synchronous PM machine types for wide constant-power speed range operation," in Conf. Rec. 2005 IEEE Ind. Appl. Soc. Annu. Meeting, Hong Kong, Oct. 2005.

[24] Z. Q. Zhu and D. Howe, "Influence of design parameters on cogging torque in permanent magnet machines," IEEE Trans. Energy Convers., vol. 15 , no. 4 , pp. 407-412, Dec. 2000.

[25] D. C. Hanselman, "Minimum torque ripple, maximum efficiency excitation of brushless permanent magnet motors," IEEE Trans. Ind. Elect., vol. 41, no. 3, pp. 292-300, Jun. 1994.

[26] J. Y. Hung and Z. Ding, "Design of currents to reduce torque ripple in brushless permanent magnet motors," in Proc. IEE-B, vol. 140, no. 4, Jul. 1993, pp. 260-266.

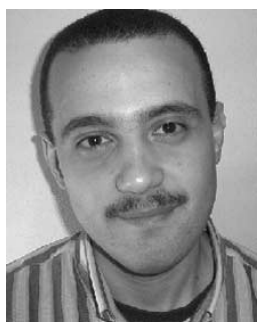

Ayman M. El-Refaie (S'95) received the B.Sc. and M.Sc. degrees in electrical power engineering from Cairo University, Cairo, Egypt, in 1995 and 1998, respectively. He received the M.Sc. degree in electrical engineering from the University of Wisconsin, Madison, in May 2002. Currently, he is pursuing the $\mathrm{Ph} . \mathrm{D}$. degree at the University of Wisconsin, Madison, in the Wisconsin Electric Machines and Power Electronics Consortium (WEMPEC) group.

Between 1995 and 1998, he was an Assistant Lecturer at Cairo University and the American University, Cairo. He participated in many projects involving the design of electrical power distribution systems. Since 1999 , he has been a research assistant at the University of Wisconsin, Madison. His interests include electrical machines and drives.

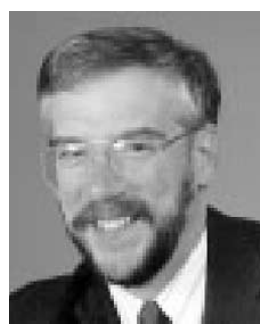

Thomas M. Jahns (S'73-M'79-SM'91-F'93) received the S.B., S.M. and Ph.D. degrees in electrical engineering from Massachusetts Institute of Technology, Cambridge, in 1974, and 1978, respectively.

He joined the faculty of the University of Wisconsin, Madison, in 1998 as a Professor in the Department of Electrical and Computer Engineering, where he is also an Associate Director of the Wisconsin Electric Machines and Power Electronics Consortium (WEMPEC). Prior to coming to UW-Madison, he was with GE Corporate Research and Development (now GE Global Research Center), Schenectady, NY, for 15 years, where he pursued new power electronics and motor drive technology in a variety of research and management positions. His research interests include permanent magnet synchronous machines for a variety of applications ranging from high-performance machine tools to low-cost appliance drives. From 1996 to 1998, he conducted a research sabbatical at the Massachusetts Institute of Technology, where he directed research activities in the area of advanced automotive electrical systems and accessories as co-director of an industry-sponsored automotive consortium.

Dr. Jahns is the recipient of the 2005 IEEE Nikola Tesla Award. He was awarded the William E. Newell Award by the IEEE Power Electronics Society (PELS) in 1999. He was a Distinguished Lecturer of the IEEE Industry Applications Society (IAS) during 1994-1995 and of the IEEE-PELS during 1998-1999. He has served as President of PELS (1995-1996) and as Division II Director on the IEEE Board of Directors (2001-2002).

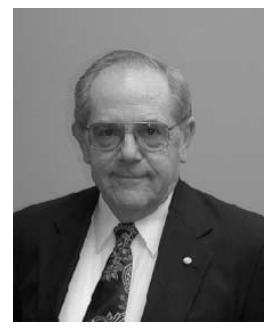

Donald W. Novotny (F'87) received the B.S. and M.S. degrees in electrical engineering from the Illinois Institute of Technology, Chicago, in 1956 and 1957 and the Ph.D. degree from the University of Wisconsin, Madison, in 1961.

Since 1961, he has been a member of the faculty at the University of Wisconsin-Madison, where he is currently Emeritus Grainger Professor of Power Electronics and Co-founder and former Co-director of the Wisconsin Electric Machines and Power Electronics Consortium (WEMPEC). He retired from full-time activity in 1996 but continues teaching part-time. From 1976 to 1980, he served as Chairman of the Electrical and Computer Engineering Department and as an Associate Director of the University-Industry Research Program from 1972 to 1974 and from 1980 to 1993 . He has been active as a consultant to many organizations and a Visiting Professor at at five universities. His teaching and research interests include electric machines, variable-frequency drive systems, and power electronic control of industrial systems. He is the co-author of two textbooks on electromechanical systems and has published over 100 technical articles on electric machines, variable frequency drives and power electronic control of industrial systems. In addition to his regular university teaching, he has been very active in continuing education and served for nine years as Chairman of the Electrical Engineering Program for the National Technological University (NTU). He has received three awards for outstanding teaching and numerous prize paper awards from the IEEE Industry Applications Society and other groups. During his career, the research and teaching program in electric machines and power electronics at the University of Wisconsin, Madison, has grown to one of the largest in the U.S. WEMPEC, which currently has over 45 industrial sponsors and receives approximately $\$ 500 \mathrm{~K}$ in unrestricted gift funds each year, has been the focus about which the entire program has developed.

Dr. Novotny is a member of ASEE, Sigma Xi, Eta Kappa Nu, and Tau Beta $\mathrm{Pi}$ and is a Registered Professional Engineer in Wisconsin. 